\author{
ARTURO REYES \\ poesías sueltas \\ ordenado y dispuesto para la imprenta \\ por Clara TRIGUEROS Boto \\ Málaga
}

\title{
NOTA PREVIA
}

El 17 de junio de 1913 moría Arturo Reyes, novelista, poeta y periodista malagueño, a la edad de 49 años. Durante ese tiempo dedicó la mayor parte de sus esfuerzos a una sola tarea: intentar triunfar en el mundo de las letras. Sin llegar a ser un autor de primera línea, como lo sería Salvador Rueda, ha conseguido al menos la gratitud de su ciudad como demuestran entre otras cosas los monumentos que se encuentran en Málaga y que nos recuerdan a su persona.

En su corta vida disfrutó de una más que discreta fama y admiración tanto por parte de la crítica como de sus colegas escritores. Entre sus reconocimientos figuran el nombramiento de Hijo Predilecto de la ciudad de Málaga en 1912', banquetes en su honor por triunfos literarios ${ }^{2}$ y el premio Fastenrathen 1911 por su obra Bética, que ganó ex aequo con Ricardo León ${ }^{3}$. Mantuvo, además, la amistad

${ }^{1}$ En 1912 fue nombrado Hijo Predilecto de Málaga junto a los también escritores Salvador Rueda y Ricardo León. Cf. Mundo Gráfico, año II, número 47, 18 de septiembre de 1912, pág. 16.

${ }^{2}$ El 1 de abril de 1901 se celebró en el hotel Inglés un banquete para celebrar el triunfo de su novela La Goletera. Cf. «Almuerzo en Honor de Arturo Reyes», El Imparcial, año XXXv, no. 12.203, 2 de abril de 1901, pág. 2.

${ }^{3}$ Cf. E. Gómez de Baquera, «Revista Literaria», Los Lunes de El Imparcial, año XLV, no. $15.757,16$ de enero de 1911. 
y consideración de importantes escritores contemporáneos como Benito Pérez Galdós, Narciso Díaz de Escovar o Salvador Rueda, tal como demuestra la intensa correspondencia que cruzó con ellos 4 .

Trabajó intensamente por potenciar e impulsar la cultura en Málaga. Creó junto a Díaz Escovar y los actores José Ruiz Borrego y Silveria del Castillo la Academia Provincial de Declamación, Música y Buenas Letras de Málaga. Esta institución se convirtió en punto de encuentro para artistas, actores, escritores y periodistas y se impartían clases de música, pintura, escenografía, guitarra o idiomas. También fue secretario de la malagueña Asociación Descentralizadora Literaria y Artística junto a Ramón Antonio Urbano Carreres. Fue además Correspondiente de la Academia de la Poesía Española, Académico Correspondiente en Málaga de la Real Academia Española y miembro de la Real Academia de Bellas Artes de San Fernando.

Aunque algunas de sus obras llegaron a ser conocidas en Hispanoamérica y se tradujeron al italiano ${ }^{6}$ y el alemán ${ }^{7}$, poco después de su fallecimiento su figura fue cayendo poco a poco en el olvido, como recordaba González Anaya en 1948 ante la Real Academia Española durante su discurso de ingreso: «En la actualidad no se lee al prestigioso literato y sus libros se sumen en el silencio, en la depresión subsiguiente a las jornadas de triunfo»».

Su labor profesional se centró en la creación de cuentos, novelas cortas y poemas donde reflejaba sus inquietudes y deseos, las costumbres de su ciudad natal y las numerosas crisis espirituales que sufriría. Asimismo, colaboró con diferentes publicaciones periódicas de la época, tanto con artículos periodísticos como con relatos o versos; en este sentido, llegó a ser director de El Renacimiento. Fue durante esta época cuando escribió en esta revista con diferentes seudónimos (Enrique Britano y Alberto Manrique), lo que le permitía participar varias veces en un mismo número bajo identidades distintas9.

La trayectoria editorial de Arturo Reyes comenzó en 1879, junto con su entrañable amigo Narciso Díaz de Escovar y otros colegas, en un libreto denominado Bocetos a la Ligera por 4 caballeros particulares; en él se recopilaban poemas satíricos escritos en torno al carnaval malagueño. No obstante, en este libro todos sus autores firman con sus iniciales, de modo que nunca veremos el

${ }^{4}$ A. Quiles Faz y A. El Founti Zizaoui (eds.), Arturo Reyes: epistolario de un escritor andaluz (1863-1913), Universidad de Málaga, 2013.

${ }^{5}$ M. I. Jiménez Morales, «La Recepción Crítica de los cuentos andaluces de Arturo Reyes (1888-1911)», en A. A. Gómez Yebra, Estudios sobre el Patrimonio Literario Andaluz (VI). Homenaje al profesor Salvador Montesa, AEDILE, Málaga, 2014, págs. 111-130.

${ }^{6}$ G. Nuñez de Arce, «Carta-Prólogo», en A. Reyes, Desde el Surco. Poesías, Librerías Fernando Fe, Madrid, 1896.

${ }^{7}$ C. Cuevas García, Arturo Reyes. Su vida y su obra. Un enfoque humano del andalucismo literario, I, Caja de Ahorros Provincial de Málaga, 1974, pág. 83.

8 S. González Anaya, Los costumbristas malagueños. Discurso leído el día 28 de noviembre de 1948 en su recepción pública, Real Academia Española, Málaga, 1948, pág. 45.

9 Todos los escritos que realizaba con seudónimos fueron posteriormente incorporados a sus libros. 
nombre completo de nuestro escritor, sino las siglas A. R. Tenemos noticia de su colaboración en 1884 en ;Viva el Carnaval! Pensamientos, Poesías, Refranes, Cuentos, Agudezas, Epigramas, Charadas y otros pasatiempos (Imprenta de la Viuda de Gil de Montes, Málaga). Pero dado que no se ha encontrado este libro no ha sido posible conocer su contribución al mismo ${ }^{10}$. Del 1885 data su primer cuento publicado, hoy también perdido, llamado «Conchita la Burrera», aparecido por entregas en el Correo de Andalucía. Lo escribió por necesidad, aunque desde entonces no dejaría nunca el oficio de escritor que tantas alegrías, y también tristezas, le daría.

Su labor literaria continuaría en 1888 con Sargento Pelayo. Bocetos de novela, primer libro de novelas cortas que vería la luz pero que pasaría inadvertido para el público y la crítica. En esta obra encontramos seis cuentos que repetiría en otra recopilación de 1892 llamada Mosaico que tampoco tendría mucho eco entre los lectores. En 1889 publicaría Ráfagas, una colección de poesías con la que iniciaba su camino en verso, si bien no lo continuaría hasta 1896 con Desde el surco. Entre tanto, la prosa de sus relatos había ocupado su inspiración: ;Estaba escrito! Novelas cortas, 1890; Mosaico, 1892; o el más famoso Cosas de mi tierra, 1893. No sería, sin embargo, hasta 1897 cuando gozara del éxito editorial con la novela Cartucherita, editada en varias ocasiones y adaptada al teatro por Jurado de la Parra en 1898. Los cuentos conformarían lo principal de su creación hasta el final de sus días, agrupándose en colecciones o en suelta. Pero los libros que podemos considerar importantes en su vida literaria serán El lagar de la Viñuela de 1897 — cuya primera edición se agotó con rapidez-, La Goletera (1900) y Del Bulto a la Coracha de 1902, que también se llevó al teatro de la mano de Vital Aza. Aunque de menor trascendencia, no podemos dejar de señalar — por lo que atañe a este trabajo - la publicación de otros poemarios: Otoñales (1904), Béticas (1910) y, el último, Romances andaluces (1912).

Gran parte de los principales títulos recogidos evocan sin lugar a dudas a Málaga. $Y$ es que es necesario tener en cuenta que Arturo Reyes sentía verdadero amor por esta ciudad que le vio nacer, que retrató con detalle en sus escenas y de la cual no quiso irse nunca. Acaso en esta última circunstancia encontremos cierto esclarecimiento sobre la escasa repercusión de su trabajo. Cuando tuvo la oportunidad de trasladarse a Madrid, donde triunfarían otros compatriotas como Salvador Rueda, su renuncia frenó sin paliativos el desarrollo de su vida profesional.

En general, la obra de Arturo Reyes se caracteriza por un doble estilo que engloba tendencias románticas por un lado y costumbristas por otro. En el primero de los casos observamos versos bellos y elegantes, sentimentales y melancólicos, donde el amor, la soledad, la muerte o la nostalgia del pasado, el romanticismo exótico de Oriente... resultan ser los recipientes en que se vuelcan las crisis existenciales que el autor tendría recurrentemente durante su vida. Pero,

${ }^{10}$ C. Cuevas García, op. cit., pág. 235. 
sin duda, será el costumbrismo la nota más distintiva de Arturo Reyes. Nos describe graciosamente a personajes pintorescos, con nombres aún más pintorescos si cabe, que conversan de modo distendido y coloquial, en ambientaciones propias de Málaga y de sus barrios. La temática se centra en romances, celos y venganzas que sacan a relucir el temperamento de sus protagonistas. Es aquí especialmente, en la viveza de sus diálogos, donde se desenvuelve su peculiar estilo, trasladando a todos los niveles -fónico, morfosintáctico y léxico- el habla coloquial malagueña.

Como ha quedado dicho, desde hace varias décadas existe un olvido generalizado de Arturo Reyes salvado en muy contadas ocasiones, tales como los centenarios de su nacimiento y su muerte, momentos en los cuales se han reeditado algunos libros suyos o que trataban sobre él. En primer lugar es necesario citar el trabajo monográfico de 1974 a cargo del profesor Cristóbal Cuevas García ${ }^{11}$ que es la base de toda investigación que pueda hacerse sobre nuestro escritor. En él se realiza un detallado recorrido sobre su vida personal y profesional trazado sobre fuentes de primera mano: testimonios y documentos familiares así como el archivo personal de Arturo Reyes. Es inexcusable punto de partida - fuente de lo sintetizado en el Diccionario de escritores de Málaga y su provincia $^{12}$ - , que puede quedar no obstante completado en ciertos aspectos con nuevas aportaciones y revisiones interpretativas. Por otra parte, la crítica se ha aproximado a la producción de este autor con las miras puestas en el ámbito del costumbrismo andaluz y malagueño. En su faceta lingüística, sobresalen los significativos trabajos de Pilar Carrasco Cantos o el conocido Vocabulario Popular Malagueño de Juan Cepas, donde encontramos abundantes referencias a sus obras ${ }^{13}$. En lo literario, cabe destacar la monografía de María Isabel Jiménez Morales La literatura costumbrista en la Málaga del siglo XIX: un capítulo del costumbrismo español ${ }^{14}$, que expone el andalucismo que se encuentra en su obra y que intentó «elevar a categoría artística el hablar del pueblo al que tanta veneración profesó, pero nunca lo logró del todo»; presta especial atención a la vertiente popular y flamenca de la obra de Arturo Reyes Alfredo Arrebola en su libro Malagueños en la literatura ${ }^{15}$. En los últimos tiempos, se ha avanzado en el conocimiento de su contexto social y de su círculo de amistades a través de la publicación de su epistolario (cf. nota 4).

${ }^{11}$ C. Cuevas García, Arturo Reyes. Su vida y su obra. Un enfoque humano del andalucismo literario.

${ }^{12}$ C. Cuevas García, Diccionario de escritores de Málaga y su provincia, Castalia, Madrid, 2002.

${ }_{13}$ P. Carrasco Cantos, «Representación gráfica de la variedad andaluza en la obra de Arturo Reyes», en R. M. Castañer Martín y V. Langüens (eds.), De moneda nunca usada. Estudios dedicados a José M. Enguita Utrilla, Fernando el Católico, Zaragoza, 2013, págs. 175-187; J. Cepas, Vocabulario Popular Malagueño, Plaza \& Janes, Barcelona, 1985.

${ }^{14}$ M. I. Jiménez Morales, La literatura costumbrista en la Málaga del siglo XIX: un capítulo del costumbrismo español, Servicio de Publicaciones de la Diputación de Málaga, 1996.

${ }^{15}$ A. Arrebola, Malagueños en la literatura, Aljaima, Málaga, 1992. 
En lo que se refiere a la reunión y publicación de sus obras tras su muerte, encontramos en primer lugar «Entre breñas», un cuento que apareció en la colección Los Contemporáneos justo en 1913. Un año después sus amigos y colegas costearon una recopilación de poemas llamada Del crepúsculo. Poesías póstumas, donde se recogen los últimos versos escritos por nuestro autor.

En 1918 se reeditó Cartucherita - su novela más famosa según hemos referido- por Prensa Popular y, en 1929, Arturo Reyes. Sus mejores versos en la colección «Los Poetas», donde se congregan poemas ya publicados en otros libros. Después de esto habría que esperar a 1946 para encontrar la reedición de El Lagar de la Viñuela por la editorial Reguera.

En los años sesenta se publicarían varias recopilaciones de nuestro escritor alentadas por la conmemoración del centenario de su nacimiento: de 1963 data ¡Lo de Siempre! y Yo soy er Tano, dos cuentos editados por el malagueño Ángel Caffarena Such; bajo el patrocinio de la Diputación y el Ayuntamiento de Málaga se publicaron Cuentos andaluces de Arturo Reyes en 1964, Novelas Andaluzas en 1965 y 1966, Poesías escogidas de Arturo Reyes en 1968. En 1970 vería la luz Doce costumbristas malagueños, obra colectiva en la que se reunían cuentos de autores malagueños como Salvador Rueda o Salvador González Anaya; Arturo Reyes quedaría representado con su título «Del Bulto a la Coracha». Finalmente, se reeditaría de nuevo Cartucherita en 1984 por el Centro de Ediciones de la Diputación de Málaga y en 2004 por la Biblioteca de Autores Españoles.

Este escueto recorrido por la trayectoria editorial y crítica del autor nos mostraría de manera evidente el carácter localista del que adolecen la mayor parte de los acercamientos y, en general, el descuido y desantención - también por falta de ediciones - que ha sufrido su producción literaria.

Como contribución al conocimiento de la obra total de Arturo Reyes, el presente repertorio recoge por primera vez un conjunto de poemas localizados en diferentes revistas y periódicos que no han sido nunca publicados en ningún libro del escritor ni en ninguna otra recopilación póstuma. La tarea, a priori sencilla, se complica cuando en el cotejo atento detectamos la publicación de ciertas composiciones idénticas bajo distinto título o variantes redaccionales. Sin menoscabo de su consulta en sus publicaciones originales - donde estos textos se acompañaban en su mayor parte de ilustraciones que representaban escenas costumbristas y que reflejaban su contenido-, el lector puede encontrar aquí compilada una parcela de la obra de Arturo Reyes de singular interés para el estudio de su evolución poética, pero poco atendida por su gran dispersión y desconocimiento. Nos hemos centrado en esta ocasión en la poesía, pero idéntica tarea tenemos abordada para los relatos, el género en que realmente despuntó. Se retoma de esta forma, aunque perfilada, contrastada y ampliada, la labor previa llevada a cabo por alumnos y profesores del Instituto de Educación Secundaria La Rosaleda de Málaga que en 2013, con motivo del centenario de la muerte de Arturo Reyes, dieron a conocer en un blog algunas obras, noticias y reseñas sueltas de nuestro autor localizadas a través de la Hemeroteca Digital Hispánica (http://arturo-reyes-aguilar-blogspot.com.es/). 
Además de esta fuente, nos ha servido de referencia la prensa periódica depositada en el Archivo Narciso Díaz de Escovar de Málaga y otras hemerotecas en red.

Debemos también agradecer a M. José Reyes Sánchez, bisnieta del escritor, el acceso al Archivo personal de Arturo Reyes, lo cual ha contribuido a conocer de primera mano su vida personal y profesional. Al mismo tiempo, agradecemos su labor de recuperación bio-bibliográfica y divulgación a partir del blog dedicado a Arturo Reyes y Adolfo Reyes, hijo de este y también escritor (http://archivoreyes.blogspot.com.es/) ${ }^{16}$.

En la disposición de los poemas que presentamos a continuación se ha seguido estrictamente un criterio cronológico, de modo que respetamos la datación de las publicaciones. Por último, en la transcripción de los textos se ha actualizado la ortografía, pero se han conservado los coloquialismos tan característicos del estilo de Arturo Reyes.

El primer poema que recogemos tiene por título «Un ruego» y se publicó en la revista Madrid Cómico el 22 de enero de 1887, año VII de la revista, número 205. Sale a la luz en el comienzo de la trayectoria literaria de Arturo Reyes cuando todavía no había publicado ningún libro. Se encuentra también, con fecha posterior, en la revista uruguaya llamada Caras y Caretas (Montevideo) el 24 de agosto de 1890, número 6, año I, tomo I. El tono vitalista y satírico reconocible en su primera etapa encuentra eco en esta composición. Figura en el Blog del IES La Rosaleda.

Seguimos con «Remember». Este poema, de curioso título en inglés, lo encontramos en El Renacimiento, revista ilustrada de la que Arturo Reyes fue director, como ya hemos mencionado anteriormente, durante los números 37 y 54 y donde utilizaría los seudónimos de Enrique Britano y Alberto Manrique. Es del 13 de enero de 1889, número 15, año II, el mismo año en que publicaba el libro Ráfagas. En este mismo número escriben los también malagueños Narciso Díaz de Escovar, en cuyo archivo hemos localizado el texto, y Ramón A. Urbano.

En La Semana Cómica aparece «A un idiota» con fecha de 22 de febrero de 1894, número 7, año II, cuando el escritor ya comenzaba a vislumbrar la fama debido al éxito de su libro Cosas de mi tierra. Es pieza que pone en evidencia los beneficios existenciales de la ingenuidad. Encontrado a través de la Hemeroteca Digital Hipánica.

\footnotetext{
16 Debemos a Josefa Reyes la confirmación de que se encuentran en el Archivo dos obras dramáticas inéditas de Arturo Reyes: El lagar de los Rosales y Entre montañas. Estas dos piezas fueron mencionadas por C. Cuevas en su estudio sobre el autor, señalando que solo vio una de ellas y sin poder corroborar la existencia de la otra por haber sido destruida (Arturo Reyes. Su vida y su obra. Un enfoque humano del andalucismo literario, II, pág. 219). Sin embargo, nosotros podemos confirmar que se conserva y que se encuentra en posesión de la familia.
} 
A continuación figura «A Dios». Refleja la crisis que sufrió en estos mismos años el escritor, que pese a que empezaba a tener cierto reconocimiento en las letras, sufría problemas económicos y una frágil y debilitada salud, dificultades que le acompañarían el resto de su vida. Este soneto se encontraba en la revista barcelonesa La Semana Cómica del 8 de marzo de 1894, número 9, año II. Ha sido una aportación cortesía de M. José Reyes. Encontramos una poesía de igual nombre en Del Crepúsculo. Poesías póstumas, pero se trata de obras completamente diferentes.

«En mi barrio» se publicó el 3 de diciembre de 1898, número 396 de la revista Blanco y Negro y se trata del primer poema de corte costumbrista de los que seleccionamos. Cuando sale a la luz esta poesía Arturo Reyes ya conoce la fama pues Cartucherita había gozado de una gran acogida entre el público y la crítica y comenzaba a ser homenajeado por ello. Es un ejemplo muy claro del género en que se especializará. Encontrada en la Hemeroteca de $A B C$. Este poema comparte título con otros que se encuentran en obras como Otoñales, Romances andaluces y Poesías escogidas. Pero no solo con otros versos sino también con cuentos cortos.

Del año siguiente es el poema «En el teatro» que encontramos en La Vida Galante, una revista de Barcelona. Y es que su hermano, Adelardo, se trasladó a la capital catalana cuando era solo un niño con su madre y ayudó a que la obra de Arturo Reyes fuera allí conocida. Aparece el 5 de marzo de 1899, número 18, año II, cuando su carrera estaba consolidándose. Figura en el Blog del IES La Rosaleda.

«El jacinto» es una poesía que vemos en el Almanaque Ilustrado, con fecha de 30 de diciembre de 1899, que pertenecía a la revista Blanco y Negro. Este anuario tenía como tema las flores de los diferentes meses del año y a Arturo Reyes le correspondió diciembre mediante el jacinto. En esta poesía se recrea el Oriente que tanto amaba y al que tanto recurría en sus poesías. En este número de Blanco y Negro participan otros escritores como Salvador Rueda o Emilia Pardo Bazán. Es pieza mencionada por C. Cuevas y tomada de la Hemeroteca de $A B C$.

En otro almanaque, en este caso el Almanaque de la Exposición Provincial de Málaga de 1901, aparecería el poema «En el Paraíso». Comparte líneas con los también malagueños Salvador Rueda, Salvador González Anaya o Ramón A. Urbano. Esta poesía tiene de particular que coinciden las dos primeras líneas con aquella del mismo nombre que se encuentra en Del crepúsculo. Poesías póstumas publicado en 1913. El tema, que es el paraíso del amor frente al paraíso bíblico, es el mismo en ambas, pero sus versiones difieren considerablemente, por lo que hemos estimado oportuno incluir aquí la primera de ellas. El texto ha sido localizado a través de la Biblioteca Virtual de Andalucía.

Continuamos con «En mi barrio (Cuadros malagueños)», que se publicó en el periódico ilustrado Nuevo Mundo del 26 de noviembre de 1903, año X, número 516. A pesar de su título nada tiene que ver con la poesía del mismo título que hemos mencionado anteriormente, excepto que la corriente literaria 
aquí usada es de nuevo el costumbrismo. Tampoco con aquellas que comparten nombre en los libros Otoñales, Romances andaluces o Poesías escogidas. Vemos que, aunque no es inusual el que los escritores usen el mismo epígrafe para diferentes creaciones, en Arturo Reyes se da de manera recurrente. Lo incluye el Blog del IES La Rosaleda.

En Blanco y Negro aparece «Patio andaluz» con fecha de 29 de julio de 1905, número 753. En esta poesía queda retratada una de las escenas a las que nos tiene acostumbrado el escritor malagueño, en un típico corralón andaluz. Los protagonistas reflejan la madurez del escritor mediante un romance sosegado y calmado, y no tan impetuoso como se vislumbraba en los primeros años de escritor del malagueño. El dibujo original que acompaña a este poema en su fuente primitiva está firmado por Huertas. C. Cuevas lo recoge, si bien con fecha de 1904. Tomado de la Hemeroteca de $A B C$. Encontramos de nuevo coincidencia en el título de la poesía con otras recogidas en los libros Del Crepúsculo, Poesías póstumas y Poesías escogidas pero que nada tienen que ver en su contenido.

Unos meses después aparece «Triste regreso» en Nuevo Mundo, el 10 de agosto de 1905, número 605, año XII. Trata aquí del sufrir de los campesinos a causa de la sequía que devasta el campo. Este poema coincide en el tiempo con una visita que hace al pueblo malagueño de Casarabonela y cuyo resultado fue un artículo en El Imparcial donde denuncia la situación del campo andaluz. Lo reseña el Blog del IES La Rosaleda.

Acabamos con «En Capuchinos», que se publica en el Heraldo de Madrid el 26 de diciembre de 1906, número 5.874, año XVII. Es un poema dedicado al barrio malagueño de tal nombre y a sus gentes. Incluido en el Blog del IES La Rosaleda. 